\title{
La poesía como lugar de memoria afropacífica en los Los versos de la Margarita, de Margarita Hurtado Castillo*
}

Fecha de recepción: 10 de noviembre de 2021

Fecha de aprobación: 23 de diciembre de 2021

\section{Resumen}

Margarita Hurtado Castillo (1917 - 1992) fue una gran caja de resonancia (receptora y transmisora) de los sonidos atrapados en los remolinos del tiempo marino: los liberaba en poemas, coplas o contando historias como grandes atarrayas. Esta investigación cualitativa, de carácter bibliográfico, tiene como objetivo caracterizar, desde una perspectiva decolonial, aspectos de la memoria colectiva de las comunidades negras del Pacífico colombiano presentes en poemas seleccionados de Los versos de la Margarita, obra póstuma de la narradora oral. Se pretende demostrar que, además de recopilar un pasado que en forma de verso expone lo que significa pertenecer a esta cultura, las composiciones de literatura oral de Hurtado actúan como discursos de resistencia que promueven conciencias colectivas, exaltan su identidad étnica y ayudan a trazar caminos grupales de emancipación de las macroestructuras del sistema de mundo occidental, de matriz colonial, racista y patriarcal.

Palabras clave: Afropacífico, discursos de resistencia, literatura oral, memoria, racismo.

Citar: Vivas Banguera, Julián y Valéria Amim. "La poesía como lugar de memoria afropacífica en los Los versos de la Margarita, de Margarita Hurtado Castillo". La Palabra, núm. 41, 2021, e13643 đohttps://doi. org/10.19053/01218530.n41.2021.13643

\begin{abstract}
Julián Vivas Banguera
Universidade Estadual de Santa Cruz (UESC), Brasil. Maestrando en Letras: Lenguajes y Representaciones en la Universidad Estatal de Santa Cruz (UESC). Integrante del Grupo de Investigación en Interacciones Sociales y Ambientales y Lenguaje (UESC). julianvivasb@hotmail.com
\end{abstract}

(iDhttps://orcid.org/0000-0003$\underline{1274-1503}$

\section{Valéria Amim}

Universidade Estadual de Santa Cruz (UESC), Brasil. Postdoctorada en Sociología por la Universidad de Beira Interior (UBI), Portugal. Profesora de Comunicación Social y del Programa de Posgrado en Letras: Lenguajes y Representaciones, de la Universidad Estatal de Santa Cruz (UESC). Coordinadora del Grupo de Investigación de Interacciones Sociales y Ambientales y Lenguajes (UESC). vamim@uesc.br

(Dhttps://orcid.org/0000-00018856-1889

* Artículo de investigación.

Este texto forma parte de una tesis de maestría en curso, centrada en el estudio de la Literatura oral producida por mujeres en el Pacífico colombiano. El proyecto es financiado por la Fundación de Amparo a la Pesquisa del Estado de Bahia (FAPESB). 


\title{
Poetry as an Afro-Pacific memory stand in Los versos de la Margarita, by Margarita Hurtado Castillo
}

\begin{abstract}
Margarita Hurtado Castillo (1917-1992) was a great resonance box, receiver and transmitter of the sounds trapped in the eddies of marine time: she released them in poems, couplets or by telling stories like big fishing nets. This qualitative research, from a bibliographic nature, aims to characterize, from a decolonial perspective, aspects of the collective memory of the black Colombian Pacific's communities showed in selected poems from Los Versos de la Margarita, a posthumous book by the oral narrator. It is intended to show that, in addition to compiling a past that in verse form exposes what it means to belong to this culture, Hurtado's Oral Literature compositions act as discourses of resistance that promote collective consciences, exalt their ethnic identity and help to trace paths of emancipation from the macrostructures of our western world system of colonial, racist and patriarchal matrix.
\end{abstract}

Keywords: Afro-pacific, discourses of resistance, memory, oral literature, racism.

\section{A poesia como lugar de memória afro- pacífica em Los versos de la Margarita, de Margarita Hurtado Castillo}

\section{Resumo}

Margarita Hurtado Castillo (1917 - 1992) foi uma grande caixa de ressonância (receptora e transmissora) dos sons aprisionados nos remoinhos do tempo marinho: os liberou em poemas, coplas ou contando histórias como amplas redes. Esta pesquisa qualitativa, de cunho bibliográfico, visa caracterizar, a partir de uma perspectiva descolonial, aspectos da memória coletiva das comunidades negras do Pacífico colombiano presentes em poemas selecionados de Los versos de la Margarita, obra póstuma do narradora oral. Pretende-se mostrar que, além de compilar um passado que em verso expõe o que significa pertencer a essa cultura, as composições de Literatura Oral de Hurtado atuam como discursos de resistência que promovem consciências coletivas, exaltam sua identidade étnica e ajudam a traçar caminhos grupais de emancipação das macroestruturas de nosso sistema ocidental de matriz colonial, racista e patriarcal.

Palavras chave: Afro-pacífico, discursos de resistência, literatura oral, memória, racismo. 


\section{Introducción}

Las formas narrativas que vuelan desde tiempos seculares con las olas del Pacífico y que hoy son leídas en las páginas nacaradas de Los versos de la Margarita, de Margarita Hurtado, llegaron a Colombia en la forma de un navío europeo. Tras el fin de la esclavitud, las comunidades africanas de la diáspora se apropiaron de las tradiciones literarias ibéricas, las moldearon con las cenizas de sus historias sagradas, las usaron para escalar los altares celestiales de sus deidades y atemperar el 'Muntú' de los nuevos mundos negros del Abya Yala'.

El sincretismo narrativo que permitió la transmisión de las memorias de las lunas cobrizas del otro lado del Atlántico también ayudó a forjar identidades colectivas e instruir formas de vivir en comunidad. La tradición oral, como en otras sociedades humanas, pasó a ser parte insustituible de su expresión y vida, y se consolidó como la herramienta que les permitió narrar la vida cotidiana, enseñar a los hijos y nietos, contar hechos reales y hablar de lo divino y lo humano. Desde entonces, poesía, cuentos, coplas, décimas y cantos son las bóvedas donde se salvaguardan visiones del pasado, tradiciones y saberes ancestrales con se alivian las penas y desafían opresiones cotidianas. En ese sentido, las formas de pensamiento afropacífico ${ }^{2}$, su historia, filosofía, aspectos mágico-religiosos y su entorno, constantemente amenazado por "violencias importadas", están permanentemente orientados y organizados gracias a la oralidad.

En esta red ancestral de narradores y narradoras orales del Pacífico colombiano, la obra de la guapireña Margarita Hurtado Castillo (1917 - 1992) emerge como una gran red que pesca en versos la memoria colectiva ${ }^{3}$ de su comunidad y promueve conciencias colectivas, estableciendo un diálogo crítico en torno a los fenómenos sociales y hechos históricos que se han producido en esta olvidada región de Colombia. Como se podrá ver a lo largo de ejercicio cualitativo de cuño bibliográfico, que tiene como objetivo caracterizar los elementos de la memoria colectiva afropacífico, presentes en poemas seleccionados de la antología poética Los Versos de la Margarita, la literatura oral de Hurtado también ayudó a trazar caminos grupales de emancipación de las macroestructuras de nuestra sociedad colonial, patriarcal, racista y clasista de Occidente.

Término acuñado por los Kuna de Panamá para referirse a los pueblos indígenas de las Américas que se traduce como "tierra en plena madurez". El uso de Abya Yala en lugar de América adquiere un doble sentido en esta investigación: una posición política y un lugar de enunciación. Es decir, se configura como una forma de enfrentar el peso colonial presente en América Latina, cuyo nombre responde a un proyecto cultural de occidentalización ideológicamente articulado en el mestizaje.

2 Proponemos el uso del identificador "Afropacífico" porque, a pesar de la falta de unanimidad en cuanto a la aceptación del prefijo "Afro", desde finales del siglo xx, el reconocimiento como etnia de las Comunidades Negras en Colombia, tras la declaración de La Ley 70, en 1993, introdujo la categoría de "afrocolombianos" en respuesta a las nuevas conceptualizaciones sociológicas en Occidente basadas en la diferenciación cultural más que en el "bilogismo" racial. Siete años después, el movimiento de grupos negros de América Latina reunidos en Santiago de Chile decidió adoptar el término "afrodescendientes", como identificador de un grupo que comparte un origen (África), una historia (la trata de esclavos) y raíces étnicas y ancestrales similares.

3 Siguiendo los postulados de Maurice Halbwachs y Pierre Nora, entenderemos a la "memoria colectiva" como una reconstrucción del pasado a la luz del presente, que se fortalece desde su base en un cuerpo coherente de individuos pertenecientes a un determinado grupo social, que cohesiona saberes culturales (normas de comportamiento y valores vividos, idealizados o prohibidos) y se condensa como el combustible principal de las identidades colectivas. El concepto hace referencia a una construcción de imágenes, apoyadas en el proceso natural del aprendizaje, que se encuentra en "evolución permanente, abierta a la dialéctica del recuerdo y el olvido, inconsciente de sus sucesivas deformaciones, vulnerable a todos los usos y manipulaciones, susceptible de largas latencias y de revitalizaciones repentinas" (Nora 10). 


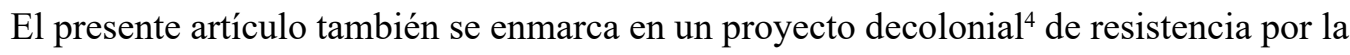
memoria que encuentra en las formas de la literatura oral afropacífico una valiosa oportunidad para rescatar la rica herencia de la palabra, su carácter de "re-existencia" histórica ante el terror del potentado colonial y su contenido somático y espiritual que ha ayudado a estas comunidades de la diáspora africana a combatir las tormentas sociales heredadas de la trata esclavista.

La ruta de navegación epistémica será la siguiente: en un primer momento, se recorrerá los caminos de los antepasados esclavizados que se apropiaron de las tradiciones literarias ibéricas y los mitos de los pueblos indígenas para dar forma a una literatura oral que se convirtió en parte insustituible de su expresión y vida. Posteriormente, se explorará el mosaico narrativo de los "Palenques literarios" afropacíficos con el fin de ilustrar cómo la copla (rítmicos cuartetos octosilábicos de tradición ibérica) llegó a convertirse en la principal forma poética utilizada por las mujeres narradoras para discutir las mareas cotidianas de su región. Finalmente, describiremos los aspectos de la memoria colectiva de las comunidades negras del Pacífico colombiano presentes en el corpus de estudio e identificaremos las fórmulas narrativas utilizadas por Hurtado para salvaguardar aquellas visiones del pasado compartidas por los miembros de la población.

\section{El mosaico narrativo de la tradición oral afropacífico}

En las culturas orales de los esteros vivos y marginalizados del Litoral Pacífico colombiano, la transmisión de la memoria colectiva se fundamenta en la palabra. Es la tradición oral, en su mar de múltiples voces que resisten las relaciones hegemónicas de poder y dominación racial, la que ha sido consagrada históricamente como vehículo de emociones, saberes ancestrales, normas sociales, filosofías y otros ideales de los pueblos negros oprimidos en Abya Yala.

Los hilos de África ${ }^{5}$ que han sobrevivido a los altibajos generacionales del tiempo marino se extienden a lo largo de los antiguos ríos que fluyen hacia el Pacífico y atraviesan la cotidianidad de los mundos negros que luchan contra el olvido. En estos pueblos orales confluyen concepciones del tiempo mítico africano y el tiempo lineal occidental, "como un crisol de los imaginarios reelaborados a partir de la colonia y la esclavización, que da como resul-

$4 \quad$ Nos adherimos al pensamiento decolonial teorizado por Walter Mignolo ("Delinking. The rhetoric of modernity") porque consideramos que solo al movilizar la mirada sobre los mecanismos de poder que tejen la historia oficial, resignificando los modos de ser y de relacionarse en el mundo, podremos dilucidar mejor las formas, causas y repercusiones de investigar el quehacer de la memoria en las sociedades que han sido históricamente subyugadas. En síntesis, lo decolonial invita a pensar otras formas de comunicación intercultural, con intercambio de experiencias y significados, que se opongan a la colonización epistemológica y a la pretensión de que las cosmovisiones europeas deben ser tomadas como universales.

$5 \quad$ El hierro de la carimba que marcó la piel de los africanos esclavizados que desembarcaron entre 1580 y 1810 en el puerto esclavista de Cartagena, desgarró sus cuerpos, pero no su memoria. Para estas civilizaciones, la tradición oral era el tronco donde se contenía la información que permitía establecer la comunicación en este sistema formado por vivos y muertos. En estos dominios del habla, los "tradicionalistas" aparecen como "depositarios de la herencia oral africana", guardianes de los secretos de la "génesis cósmica y las ciencias de la vida"; su prodigiosa memoria les permitió convertirse en archiveros de hechos pasados, transmitidos y reconstruidos a través de largas narraciones (poemas, refranes, cuentos, leyendas, mitos), siempre disponibles en la memoria, y rigurosamente cargados de detalles (escenarios, personajes, diálogos, disfraces, etc.) del evento para ser recordado (Hampaté Bâ). 
tado un enorme corpus de tradición oral que sigue renovándose, adaptándose en medio de las influencias modernizantes y la desterritorialización" (Vanín, Una mirada a la tradición 5).

Los relatos orales que versan sobre pasados colectivos, lineales o míticos, son el resultado de una metamorfosis cultural cocinada en Abya Yala e influenciada por elementos de supervivencia de la memoria "corporal" africana, en sincretización con elementos indígenas y europeos, resignificados por los hijos del mestizaje en el "Nuevo Mundo". Motta González asegura que en esta simbiosis confluyen los relatos africanos sobre las vicisitudes de la vida, la relación entre el hombre y la naturaleza y las fuerzas sobrenaturales, con relatos indígenas sobre el origen del mundo y con narrativas ibéricas ligadas al enamoramiento y las relaciones sociales (13). Los europeos también contribuyeron con sus tradiciones literarias a la definición morfológica de poemas, coplas y décimas que se componen a la sombra de los manglares del Pacífico

Este sincretismo narrativo secular se escucha en encuentros cotidianos o festivos, y se expresa a través de literaturas orales que transmiten la memoria de la vida en los esteros o denuncian las realidades accidentadas que enfrentan hoy muchas de estas comunidades. El piragüismo se realiza a través de representaciones de la "historia contada" en narrativas con las que cientos de narradores reafirman identidades étnicas, transmiten sentimientos, estructuras de parentesco, controles sociales, condiciones materiales de vida, formas de trabajo y producción, y jerarquías y mecanismos de poder ancestral (Motta González 23).

Desde un punto de vista metódico, el trabajo de narradores y narradoras orales afropacíficos podría explicarse en tres etapas: primero, él o ella debe investigar, preguntar qué sucedió y vislumbrar cómo este hecho afecta a su comunidad. Posteriormente, los "tradicionalistas" pasan este hecho histórico por un filtro creativo del que emerge transformado y enriquecido con un significado local y personal. Finalmente, declaran su creación (versos, coplas, décimas) ante la comunidad. Solo entonces, luego de ser repetidas, interpretadas y aceptadas en innumerables ocasiones, las narraciones toman su lugar en el pedestal reservado a las grandes composiciones orales: la memoria colectiva de su comunidad (Oslender 214).

Las narrativas que nacen de este diluvio creativo también presentan variaciones fonéticas, morfológicas, sintácticas y léxicas que enriquecen la lengua española y son una ventana a los procesos de resistencia lingüística desarrollados desde el paso de sus antepasados esclavizados por el Atlántico Negro. De esta forma, los decimeros, versadoras, copleros y cuenteros están encadenados a la "esencia vital" de estas comunidades como el río al mar. Ellos y ellas son sabios centinelas que ayudan a inventar diariamente "el regreso al seno materno del África donde el bisabuelo dejó enterrado su ombligo" (Revelo Hurtado, Revelo González y Revelo González 23). 
Pero, ¿cuáles son las características de las composiciones de literatura oral ${ }^{6}$ en los "Palenques literarios" del Pacífico colombiano? Prado Paredes lanza sus redes epistemológicas para explicar que, en estas comunidades, esta categoría se refiere a las tipologías y composiciones literarias que se crean para ser difundidas oralmente a través de una cadena de transmisores, depositarios y recreadores de una visión de pasado colectivo, compartida por los miembros de la población:

Cuando hablo de literatura oral, hablo de un cuerpo de memoria colectiva, de un archivo donde se fundamenta el complejo de nuestra identidad. Es la visión de la comunidad, la trasmisión, la posibilidad de hablar y escuchar en el mismo código. Es el conjunto de formas en las que se expresa un sector de la oralidad de un pueblo. Es su conocimiento, su sabiduría (Prado Paredes 193).

Aunque autores como Walter Ong se han opuesto al uso de este término, considerando que llamar a estas creaciones "literatura oral" revela una "incapacidad para representar ante nuestro propio espíritu una herencia de material organizada en forma verbal, salvo como una determinada variante de la escritura" (Ong 21), es importante aclarar que lo que se entiende como literatura oral en las comunidades afropacíficas responde a la necesidad epistémica de preservar el sentido de creación artística implícito en la idea moderna de la literatura, porque solo así se puede explicar la creación ficcional y la recreación de la realidad, narrativa, lírica o dramática, que una persona o un pueblo desarrolla a través de formas poéticas orales (Freja de la Hoz 22).

En su esbozo teórico de literatura oral, Freja de la Hoz destaca que, para que este tipo de narración se clasifique de esta manera, debe responder a tres características: primero, aunque se pueda identificar al autor (o la autora) la composición debe pertenecer a las personas, son ellos quienes se apropian de ella y la transmiten, transformándola, dándole el toque personal, la subjetividad, de quien la reproduce. En segundo lugar, desde su creación, la obra debe estar destinada a ser publicitada oralmente. Finalmente, en tercer lugar, hay que entender que estas no son producciones estáticas en papel, al contrario, la literatura oral cambia cada vez que alguien la transmite. "Al contrario de lo que está escrito, (lo que está escrito está escrito), lo oral no es estático, lo oral está en constante movimiento: en cada reproducción de lo oral hay cambios" (Freja de la Hoz 23, 24).

$6 \quad$ Al utilizar aquí el término "Literatura Oral" y no sus variantes lingüísticas como "Oralitura" u "Oratura", buscamos rescatar el valor artístico, discursivo y de "literariedad" de las formas narrativas de la tradición oral afropacífica que, invisible y despreciada durante siglos por la Colonialidad del Saber, debe entenderse, en palabras de Manuel Zapata Olivella, como una valiosa "tradición literaria otra" en la que confluyen visiones culturales, proyectos de resistencia decolonial que rechazan las ideas reduccionistas en torno a lo "negro" y promueven el rescate de sus identidades étnicas. Categorizar estas creaciones como formas de "Literatura Oral", con todo el peso ontológico que esto representa en Occidente, nos permitirá también caracterizar cómo se yuxtaponen elementos vinculados a la historia, el sufrimiento, la subordinación y la "fuerza del espíritu" de estas comunidades, en confluencia o diferencia con otros sujetos subalternizados, racializados y marginados.

7 Valderrama Rentería define los "Palenques Literarios": como espacios públicos afrocolombianos de las comunidades de habla y pensamiento que sirvieron para la construcción cultural del territorio. El palenque literario es una metonimia que apela al pensamiento libertario de los grupos cimarrones ante la continuidad histórica de los conflictos vinculados a la trata de esclavos que aún permean estas comunidades (106). 
En cuanto a los géneros de literatura oral de las comunidades negras del Pacífico, es en las tres macrocategorías expuestas por Prado Paredes donde se encuentra una suculenta recopilación conceptual, casi enciclopédica. La cartografía narrativa realizada por la investigadora clasifica estas producciones en: contadas, rezadas y rimadas. En el primer grupo están los "Casos" (historias reales relacionadas con personajes, héroes culturales o míticos) y los "Cuentos": romances de la tradición literaria europea, historias humorísticas sobre la vida cotidiana de la comunidad, fórmulas del "chamanismo" e historias sobre príncipes y princesas inspiradas en los mundos de hadas occidentales. Más adelante, la investigadora establece el "Secreto" y la "Oración" como producciones rezadas y las define como fórmulas recitadas "aplicadas para encantar o «hechizar» con filtros de amor u odio" a un sujeto específico (Prado Paredes 193, 194).

El abanico de formas narrativas afropacífico se expande en las producciones rimadas. En el primer subgrupo (forma Cantada), Prado Paredes agrupa los "Arrullos" (canciones de cuna para niños o divinidades), los "Alabaos" (canciones fúnebres para adultos), los "Chigualos" (canciones fúnebres para niños) y los "Versos animados por la marimba", un instrumento musical tradicional. El segundo conjunto (forma Dramatizada) engloba "Loas" y "Juegos tradicionales", y el tercero subgrupo (forma Recitada), comprende desde "Dichos", "Enigmas" y "Proverbios", hasta "Coplas", "Versos" y "Décimas" (194). En estas últimas formas narrativas, en particular, se encuentran prácticas de transmisión memorial que apelan a la descripción de "lugares-regiones de la memoria" (Candau 156), al recuerdo de tradiciones, a la conmemoración de eventos axiales y aplicación de prosopopeyas para preservar visiones endógenas del pasado colectivo y, en consecuencia, estructurar identidades étnicas.

\section{Coplas y cantos de guardianas del pasado}

Si en los pueblos negros del Pacífico los hombres narradores son decimeros o centinelas que conducen con sus remos los viajes por los esteros de la memoria, las mujeres narradoras se asemejan a divinidades acuáticas que emergen a la superficie para iluminar, guiar, proteger y mantener vivos con su canto los holocenos del pasado colectivo:

Las mujeres afropacíficas se convirtieron así en los griots que conservan en sus recuerdos milenarios la fuerza interna de sus aldeas y la huella mágicoreligiosa; ellas cuidan la memoria de la africanidad. En ese mundo de la oralidad son las tejedoras mágicas de la palabra. Son las maestras que con sus voces les enseñan a los infantes nautas las reglas de convivencia, el origen del mundo, los abrazos de la felicidad que les inunda el corazón de peces de mil colores y también los alabaos de tristeza que humedecen por siempre y para siempre la existencia (Revelo Hurtado, Revelo González y Revelo González 24).

El follaje de las composiciones orales de las mujeres es tan diverso como sus mundos. Si bien muchas narrativas abordan los giros y vueltas de la vida cotidiana y las relaciones comunitarias, otras se enfocan en denunciar realidades complejas, recordar tragedias, describir sus "lugares de memoria", celebrar sus identidades étnicas y exteriorizar las experiencias que las atraviesan como mujeres negras nacidas en esta convulsionada región de Colombia. Las guardianas del pasado administran ritmos en giros lingüísticos y sonoros, improvisan y 
ejecutan impecables creaciones y piezas cantadas, como arrullos, chigüalos y gualíes. También son hábiles para componer coplas epigramáticas altas, largas o cortas, o Versos sobre las artes del amor, que apelan a la argumentación para discutir situaciones o para incitar a la competencia (Motta González 30).

Es imperante acotar que por "lugares de memoria" nos referimos a espacios privilegiados del recuerdo, donde la memoria y la identidad se concentran, quedan como inscripciones, monumentos o documentos y funcionan como recordatorios, es decir, actúan como signos de recuerdo que ofrecen soporte para la memoria defectuosa, sirven como un sustituto silencioso de la memoria muerta y constituyen referencias perennes percibidas como un desafío en el tiempo (Ricoeur 64). En palabras de Joël Candau, las narrativas que versan sobre otros lugares de la memoria (playas, bosques, mares, esteros, ciudades, etc.) también contribuyen a la afirmación de las identidades regionales al referirse tanto a la geografía como a "una historia, mitos y narrativas legendarias relacionadas con este o aquel lugar en particular, siempre constituidas por varias capas de memoria" (157). En consecuencia, es por su tono confesional y de recordación innato, soporte para el diálogo con las imágenes que componen la memoria, que las composiciones literarias (orales o escritas) ganan su lugar secular en la escalera de los lugares de la memoria.

En cuanto a las coplas, evangelio importante en el sincretismo narrativo oral de los pueblos afropacífico, sobra decir que estas formas poéticas también arribaron al Abya Yala en un barco europeo. A partir de la conquista territorial, ideológica y cultural del nuevo mundo por parte de los colonizadores ibéricos, la copla, con su rima diáfana y su fraseo repetitivo, se constituyó como el principal medio de comunicación de las ideas de evangelización y aculturación implantadas en la piel de los subalternizados (mestizos y afrodescendientes), que posteriormente se apropiaron de ellas y las modificaron para narrar sus propios mundos (Freja de la Hoz 92). Al llegar al Pacífico, las coplas se convirtieron en el instrumento a través del cual las mujeres podían expresar sus vivencias y emociones: "En la copla, la mujer canta de manera libre, desatada de toda ligadura, con el propósito de agradar y acertar" y cuestionar; cada poema es una historia de la cotidianidad, de lo individual y lo colectivo (Motta González 37).

Aunque estas deidades acuáticas que protegen los ecosistemas de la memoria han existido desde tiempos inmemoriales, pocas versadoras y copleras han sobrevivido a la luz desgarradora de las sociedades patriarcales occidentales. Durante el siglo xx, solo narradoras como Margarita Hurtado, Ninfa Castillo, Mercedes Montaño, Ana Francisca Hernández y Silvestre Hernández lograron desafiar el silenciamiento histórico al que fueron sometidas las feminidades negras en las instituciones culturales y literarias para convertirse en ilustres "natas", maestras del canto y las narrativas, y grandes difusoras de la memoria colectiva de sus comunidades.

\section{Los mundos negros de los versos de Margarita}

Los versos de la Margarita es una de las obras sagradas de la literatura oral del Pacífico colombiano. El libro, publicado por la Alcaldía de Buenaventura cinco meses después de la muerte de Margarita Hurtado, es una recopilación de coplas, poemas y cuentos compues- 
tos por la "Mamá Grande" a lo largo de sus setenta y cuatro años de vida. Los archivos y transcripciones de los poemas fueron meticulosamente conservados por Rosa Joél Jímenez, esposa de su hijo Demetrio, quien creó un relicario narrativo compuesto por manuscritos, hojas mecanografiadas e impresas, recortes de periódicos, cartas y breves recopilaciones que la narradora hizo de versos tradicionales que hoy son parte de la memoria colectiva de las comunidades afropacíficas.

En el primer capítulo del libro, "Margarita y el mar", se identifican versos en los que la autora establece al Pacífico, su región madre, como la principal fuente de inspiración de sus composiciones de literatura oral. Este territorio, "con sus negros y su folclor / y su cántaro de guarapo / y el ritmo de su tambor", fue el espacio material, simbólico y funcional elegido por Hurtado (27) como organismo unificador de las conciencias colectivas que emanan de sus versos. En sus composiciones, la narradora describe geografías, fauna, flora y gastronomía de mundos donde el agua de los ríos y mares es la que guía física y simbólicamente la vida en los esteros e inspira los cantos de voga, cuentos, décimas y mitos que hacen posible la construcción y exteriorización de la memoria colectiva.

El piragüismo narrativo por la geografía del Pacífico propuesto por Hurtado en "Coplas de todos las conchas" ejemplifica la fluidez de las composiciones que utilizan el pincel de la palabra para exaltar la diversidad de la región y rechazar los discursos históricos racistas y marginales que, como el pronunciado por el expresidente Laureano Gómez, pintaron al Pacífico como una costa de "salvajes", con "lluvia implacable que lo pudre todo", "vegetación fofa", donde "ni se ve la posibilidad de que pueda existir una cultura humana de importancia" (12). Los versos de la narradora describen, con excepcional destreza retórica y dicción afropacífica, plantas endémicas, fauna, sitios representativos y gastronomía tradicional de las poblaciones asentadas a lo largo de los principales ríos (Napi, Micay, Naya, Atrato, Anchicayá, Timbiquí, Saija, Yurumanguí y Cajambre), los cuales actúan como lugares de memoria, reconocimiento social y político, individual y colectivo de las comunidades negras del Pacífico:

\section{Coplas de todas las conchas}

$$
\begin{aligned}
& {[\ldots]} \\
& \text { Bajando al río de Guapi } \\
& \text { pensé irme hasta Sanquianga. } \\
& \text { a coger unos piacuiles } \\
& \\
& \text { y varias docenas de pianguas }
\end{aligned}
$$

8 El piacuil es una concha marina parecida a un caracol que se encuentra en los lechos de raíces de los manglares del Pacífico.

$9 \quad$ La piangua (Anadara tuberculosa y Anadara similis) son moluscos bivalvos que se distribuyen en el Pacífico, desde Baja California hasta Perú, asociados al ecosistema de manglar. Este alimento es ampliamente consumido por los pueblos afropacíficos y comúnmente asociado a su identidad étnica. 


\begin{abstract}
En Naya comen papachina ${ }^{10}$, en Yurumanguí pringamosa ${ }^{11}$, en Anchicayá la chigua ${ }^{12}$ que cocina misiá Rosa.

Para Cajambre el guarapo, bacaimonte ${ }^{13}$ y pepepán ${ }^{14}$ y en la guerra de los mil días balseaban como caimán.
\end{abstract}

(Hurtado 31).

Se infiere que esta "Ilíada" a través de los mundos afropacíficos narrados en los versos de Hurtado podría estar inspirada en "La concha de almeja", una famosa décima de la tradición oral de la región que narra la historia de un hombre que navega por los cinco continentes en busca de una "coteja" (esposa):

\title{
$[\ldots]$
}

Yo me embarqué a navegar

en una concha de almeja

a rodiar el mundo entero

a ver si hallaba coteja.

Salí de aquí de Tumaco

con rumbo a Buenaventura

yo no embarqué un cargamento

porque la mar estaba dura.

[...]

Con viento que a favor sopla

atravesé a Casa Viejas

y muchas ciudades lejas

las visité en pocos días

navegando noche y día

en una concha de almeja.

(Citado en Oslender 215-216).

10 Papachina es el nombre que se le da en algunas partes de Colombia a la especie vegetal Colocasia esculenta, que crece principalmente en los humedales de la región costera del Pacífico.

11 La pringamosa (Urtica dioica) es una "maleza" muy utilizada en la cocina tradicional del Pacífico debido a sus aparentes propiedades beneficiosas para la salud de las personas. También se utiliza como repelente contra pulgas y moscas.

12 La chigua o zamiaceae es una llamativa planta que tiene una amplia copa de flores que puede alcanzar los seis metros aproximadamente y se utiliza en algunas comunidades del Pacífico con fines medicinales o como planta ornamental.

13 Inferimos que por "bacaimonte", Hurtado se refiere a la 'Vaca de Monte', tapir o tapir amazónico, un mamífero ampliamente consumido en el Pacífico y cazado por su piel y grasa.

14 El pepepán (Artocarpus camansi) es una fruta tradicional en la dieta de la costa del Pacífico, que tiene un alto contenido en carbohidratos, vitaminas, minerales y aminoácidos. 
En ambas composiciones, además de fijar a la costa del Pacífico como punto de partida, la narración es discontinua en el tiempo y el espacio, y se apela a elementos étnicos impregnados en la memoria colectiva de los habitantes. Las referencias geoespaciales utilizadas en estas "crónicas rimadas" de viajes reales o imaginarios adquieren un significado real y tangible a partir de las vivencias concretas de los afrocolombianos con su universo acuático que se plasma constantemente en la interacción con los demás, al mismo tiempo que adquiere características propias y diferenciadas de sociedades vecinas (Oslender 214).

Las coplas que tratan de la red de viajes marítimos y fluviales aparecen en este ecosistema representativo de la literatura oral como creaciones en las que se enfatiza la diversidad y la flexibilidad en las formas de acceso, apropiación y gestión de espacios donde no se permiten límites o compartimentos fijados en el tiempo. La figura del "río" en las composiciones de Margarita Hurtado debe leerse, entonces, como un elemento organizador y accionador de los procesos de integración y circulación de los hombres y mujeres afropacíficos, así como de las ideas y valores sobre los que se sustentan estos mundos culturales.

Por otro lado, las referencias a la gastronomía, repetitivas en los poemas en los que Hurtado busca exaltar las tradiciones de su "región memoria", responden a que para estas comunidades la cocina tradicional es un patrimonio ligado a su ascendencia africana y debe transmitirse a las generaciones futuras, porque si desapareciera, sería también el comienzo de la desaparición de su cultura. La alimentación estaría íntimamente ligada a factores relevantes para la cohesión y construcción de las identidades comunitarias, pues en cada receta se entrelazan las prácticas agrícolas, pesqueras y recolectoras del territorio, que confluyen en un acto de apreciación que representa su resistencia a las influencias de culturas extranjeras. En este sentido, celebrar platos y bebidas tradicionales es también sinónimo de defender el territorio, su autonomía y su identidad étnica (Ministerio da Cultura 36).

La receta de la resistencia comunitaria, cocinada en el fuego de la palabra, también se saborea en las trece estrofas rítmicas de cuartetas octosilábicas que componen "Campesino endomingado". Hurtado describe en este poema a un sujeto afropacífico que migró del campo a los principales centros urbanos de la región y que al regresar a su pueblo rechaza elementos importantes de su identidad étnica, incluida la comida tradicional:

\section{Campesino endomingao}

Algunos porque han salido

de su río pa〉 la ciudad, se olvidan de que han comido canchimalo y mozongá.

$[\ldots]$

Cuando el negro está en el monte

frente de su canalón,

su comida es malangá

y su caldo de bocón. 
Pero cuando llega al pueblo

da unos pasos hasta el fogón,

yo quiero mi desayuno

chocolate y chicharrón.

(Hurtado 20).

Las huellas de variantes dialécticas del habla local presentes en los poemas transcritos en la antología son también un elemento a destacar. Abrazar el dialecto de los pueblos afropacíficos (elipse de sílabas y fonemas "RA" y "S"; "pa" en lugar de "para"; asimilación de fonemas $/ \mathrm{i} /=/ \mathrm{r} / ; / \mathrm{r} /=/ \mathrm{d} / ; / \mathrm{r} /=/ 1 / ; / \mathrm{j} /=/ \mathrm{s} /$, etc.) representa para Hurtado (y para la mayoría de los autores de literatura oral afrocolombiana) un instrumento de comunicación, poder, resistencia, pensamiento, emoción y acción que sirve para revelar la cosmovisión de su etnia, fortalecer su identidad y hacer sus mundos "realidad" (Lawo-Sukam 46) Se trata de un español impregnado de variaciones fonéticas propias de las lenguas africanas que hablaban sus antepasados esclavizados.

Cabe señalar que, nuestras lecturas decoloniales sobre los mundos afropacíficos pintados por Hurtado rechazan los postulados reduccionistas de los estudios antropológicos del siglo $\mathrm{xx}$, que retrataron las comunidades negras del Pacífico colombiano como "campesinos", invisibilizando su especificidad cultural y dificultando su definición como etnia con las consecuencias políticas y legales que ello conlleva. En "Campesino endomingao", por ejemplo, se observa una ventana al pasado que nos ayuda a identificar los entreverados del fenómeno de la "desruralización" que se intensificó desde 1940 en la región, tomando en cuenta las complejidades de los contextos urbanos del Pacífico (y la población migrante en las grandes ciudades) y las implicaciones de estos procesos para la formación de las sociedades afropacíficas actuales, tanto en la región como en el exterior.

Son muchos los remolinos sociales que estimularon el fenómeno migratorio en las comunidades negras del Pacífico. A fines de la primera mitad del siglo xx, la llegada del capital agroindustrial a la costa — promovida por pequeños colonizadores del Valle del Cauca, Antioquia, Bogotá y los Llanos- generó nuevas formas de explotación de los recursos locales y la proletarización de campesinos que abandonaron su modelo económico tradicional (agricultura, caza, pesca, madera) por falta de recursos o asistencia técnica necesaria para sobrevivir a las nuevas estructuras de producción, trabajo y comercialización que comenzaron a ser impulsadas por las políticas neoliberales en la región (Hoffman 57). Asimismo, la generalización de la escolarización, la difusión de los medios de comunicación y la aceleración de la emigración contribuyeron a la descomposición paulatina del tríptico de cohesión comunitaria ancestral (residencia-parentesco-trabajo), cocinando así la salida de las familias de sus territorios, ya que migraron a las ciudades (Buenaventura, Tumaco, Cali y Quibdó) para acceder a la modernidad y dejar de invisibilizarse en un país que, aunque impregna la vida cotidiana del Pacífico, también se percibe ausente (Vanín, Alianzas y simbolismos 18).

En sus acuarelas de los mundos negros del Pacífico, Margarita también suma al sancocho de elementos que componen su identidad étnica un conglomerado de prácticas cultura- 
les como lo son los ritmos musicales, bailes e instrumentos tradicionales que dan vida a su comunidad. El Currulao y sus componentes aparecen en este paisaje como un epítome de la cultura de las poblaciones sureñas de la región en el que confluyen la ascendencia, la festividad y los debates en torno a la moral y la consolidación de las relaciones socio-afectivas. La 'Mamá Grande', siguiendo las explicaciones de su mentor Teófilo Roberto Potes, esbozó en siete estrofas, con prosodia afropacífico, los principales componentes del Currulao:

\title{
Como se hace un currulao
}

\author{
Teófilo Potes fue el hombre \\ predileto y preparado, \\ y él anduvo en todas partes \\ presentando el currulao. \\ $[\ldots]$ \\ Salieron a bailar las viejas \\ con sus viejos al salón, \\ con anchas naguas de letín \\ y faldas de bolerón. \\ Con guasá, cununo y bombo, \\ flauta marimba y tambor, \\ dos negras cantando fondo \\ biche, guarapo y valor. \\ (Hurtado 26).
}

A partir de la segunda mitad del siglo xx, el uso del currulao como bandera de identidad de estas comunidades también respondió a un proyecto político "afrogénico" que buscaba resaltar, afirmar y visibilizar los componentes de su cultura que se pueden pensar como parte de un "legado africano", interpretado como una pieza del pasado moldeada a las medidas del presente y que apela a la tradición para convertirse en pieza clave del rompecabezas de la identidad (Ochoa, Convers y Hernández 46). En este contexto, el currulao y la marimba (instrumento traído por los antepasados africanos según relatos inscritos en la memoria colectiva) emergen como elementos demarcadores de la cultura ancestral, vinculados a los espacios rurales y a la memoria de los y las "tradicionalistas" que deben ser transmitidos, enseñados, celebrados y legitimados de generación en generación, como un conjunto de sistemas organizados de pensamientos, prácticas y tradiciones rituales que subsisten a pesar de los asedios del tiempo. Como afirma Lawo-Sukan, se trata de un valioso acto de "resistencia contra el poder dominante" que durante siglos redujo a estas creaciones a un "arte bárbaro y salvaje" (48).

Los poemas que resguardan en verso la memoria de un pasado tormentoso que regresa con las inevitables mareas del tiempo, para mantener cohesionadas las identidades colectivas, son otro elemento característico de la obra de Margarita Hurtado. En al menos cinco composiciones compiladas en Los versos de la Margarita, la autora, con el rigor investi- 
gativo y la precisión discursiva de las narradoras afropacíficas, realiza cuidadosas crónicas rimadas que sintetizan los detalles de las tragedias que marcaron la historia e influenciaron el diseño de hojas de ruta para el futuro comunitario. Prueba de ello, son las veintitrés estrofas de "Tragedia en la Bocana" en las que la narradora condensó el recuerdo de una de las peores catástrofes ancladas en el alma de las comunidades negras del Pacífico colombiano. El poema, transcrito por los compiladores del libro en un estilo que se asemeja más al de los romances de tradición oral afropacífica, se basa en la prosodia, la dicción, el ritmo y la narración omnisciente para describir los detalles del doloroso naufragio de los más de 200 tripulantes del barco "El Vencedor" en la bahía de La Bocana (Buenaventura), al finalizar la tarde del domingo 3 de septiembre de 1961:

\section{Tragedia en la Bocana}

Septiembre primer domingo,

fecha tres pa> no olvidar;

"El Vencedor", el mismo

de otro accidente fatal,

ahora deja a cien familias

enlutadas en su hogar.

$[\ldots]$

Desde Bazán divisaron

la vuelta que el barco dio

y también cuando flotaron

los que mi Dios no llamó,

y en cuanto aparato hallaron

fueron a prestar protección.

(Hurtado 37-39)

El naufragio de "El Vencendor", registrado en su momento en los principales medios de comunicación del país como uno de los peores accidentes de la historia del Pacífico, es hoy parte irrenunciable de la historia del pasado universal de la región y se entrelaza en los procesos de formación de su comunidad imaginaria. Documentos oficiales indican que, la embarcación que salió del i Festival Nacional de Arte se hundió luego de transportar el doble de pasajeros permitidos, dejando el triste saldo de sesenta y cuatro muertos. El dolor por el siniestro también quedó depositado en las notas melancólicas de un currulao ${ }^{15}$ compuesto por Teófilo Potes que, en compañía de los versos de Margarita, ayudan a mantener vivo el recuerdo de esta tragedia en la memoria colectiva del pueblo afropacífico:

15 Como formas de tradición oral, las canciones de currulao también apelan a historias cotidianas, costumbres, gastronomía y recuerdos de las tragedias de los mundos negros del Pacífico Sur para narrar, al ritmo de la marimba, los detalles de terremotos, tsunamis e incendios que han impactado estos territorios. "Obras-pueblo" como "A Tumaco lo quemaron", "Buenaventura se quema", entre otras, han trascendido de generación en generación, ya que se entonan en celebraciones, eventos culturales y han ayudado a mantener viva esa memoria colectiva de las tragedias que mantienen unida la identidad étnica afropacífica. 


\begin{abstract}
Si sabe que el agua moja
porque no se arremangó?

este fue el castigo

que mi Dios mandó.

Diciembre primer domingo

una más nos sucedió

el barco de Ricardo Dueñas

se llamaba El Vencedor".
\end{abstract}

Nos encontramos, una vez más, ante composiciones de literatura oral que emergen como archivos donde se establecen visiones del pasado colectivo que irrigan los corales de la identidad étnica afropacífica con su nepente vital. Cada poema debe ser leído como un valioso documento histórico que busca resguardar la memoria de los sufrimientos compartidos a lo largo de varias generaciones por los miembros de la comunidad, como una forma de mantener viva la llama de su "espíritu" identitario y prevenir tragedias similares en el futuro.

\title{
Versos de resistencia
}

En las creaciones de literatura oral recopiladas en Los versos de la Margarita, el "yo poético" de Hurtado se extiende más allá de un "yo", integrando la voz de los otros, pues es en esta región-memoria donde se cultiva el espacio biográfico en el que se articulan nuevos parámetros entre el vínculo social y un ideal de comunidad, una vez que se amplía el conocimiento de los demás y, en consecuencia, de uno mismo. Esto se observa con más detalle en poemas como "Esta grave situación", "Esta vida insoportable" y "Los millones que producen Buenaventura y su suerte", en los que la narradora viste el traje sagrado de las "autoras-pueblo", que denuncian en sus composiciones las complejas realidades que asolan sus comunidades, al mismo tiempo que participan en la construcción y articulación de conciencias políticas y espacios de resistencia (Freja de la Hoz 155):

\section{Esta grave situación}

Vengo a hacerte esta pregunta, me la vas a responder:

¿cuantos pesos se gasta al día una familia en comer?

Otra cosa has de explicarme sin irme a contradecir ¿cuanto valía un kilo de carne cuando se podía vivir?

Esta situación actual no se puede comprender, 
pues no hay en qué trabajar

ni plata con qué comer.

(Hurtado 23-24).

El poema anterior está compuesto por veinte estrofas que se entrelazan en este ejercicio de interpretación como una ventana a la visión del pasado que tuvo el subordinado sobre la vida en Buenaventura en 1961, año en que la autora firmó la composición. Se trata de una composición de literatura oral en la que, además de movilizar memorias colectivas para reflexionar sobre el pasado comunitario, se articulan procesos de conciencia colectiva con el objetivo de cuestionar las condiciones de opresión en las que se inscribe su vida cotidiana y se alienta a actuar contra estas injustas estructuras políticas y económicas, proyectando así caminos futuros de resistencia (Oslender 208).

Se trae aquí las palabras del pensador chocoano Rogério Velásquez para reafirmar que estos mecanismos de resistencia anclados al poder emancipador de la tradición oral han sido orquestados desde la época colonial:

Hállanse en estos versos complejos raciales, diferencias de castas, choques de culturas. El africano que empezaba a escalar la cuesta que conduce a la dignidad humana, y la civilización europea del blanco que encaraba los problemas de acuerdo con ella y con las circunstancias, produjo esta lucha de criterios que, plasmados en decires rimados, se quedó en la memoria de mineros y terratenientes del extinguido Cauca grande, emociones que saltan de tarde en tarde como derrotero de conducta o como garfio que escarba doloroso un poco más adentro de la carne (Velásquez 13).

Retornando la mirada a los márgenes narrativos de Los versos de la Margarita, se observa que es imperativo caracterizar cómo la exteriorización de esta conciencia política se lleva a cabo a través de formas poéticas tradicionales. En este sentido, siguiendo el esquema metodológico de narradores y narradoras afropacíficas, se identifican los siguientes elementos en los versos políticos de Hurtado, principalmente, los que describen el paso de procesos electorales que marcaron el clima político de la región y del país durante la segunda mitad del siglo xx. Primero, se observa que la poeta, con el rigor de los historiadores y el oído atento de los "tradicionalistas" de la región, describe con precisión los hechos, realiza entrevistas y contrasta fuentes de información "oficiales" (periódicos, comunicaciones estatales) con testimonios de testigos presenciales. En un segundo momento, Hurtado pasa estos hechos por un filtro creativo del que salen en forma de versos con rimas precisas y con títulos similares a 'Lo que vi en las elecciones' o 'La campaña de los políticos'. En algunas creaciones, el “yo poético" de la autora se presenta en la forma tradicional del narrador omnisciente y extradiegético; sin embargo, son más comunes los poemas en los que se observa que el discurso está claramente permeado por filiaciones ideológicas relacionadas con el proyecto de resistencia política, articulado conjuntamente entre la narradora y su comunidad.

La prosopopeya memorial ejecutada por la autora en poemas como sobre la vida de "hombres y mujeres Estado" también debe entenderse aquí como un elemento característico de la obra de Hurtado. En ocho poemas recopilados en la antología, la narradora configura una idealización y mitologización de las imágenes de "personajes modelo" fallecidos (líderes 
políticos y religiosos, gestores culturales, deportistas famosos, etc.) que guían con su legado los caminos futuros de la comunidad y, por lo tanto, deben ser ubicados en el punto más alto de la pirámide de la memoria colectiva (Candau 143). Entre sus "poemas/monumentos" orales se destaca el escrito en memoria de su tutor, Teófilo Roberto Potes (1917 - 1975), "hombre ideal" que fue "grande en toda Colombia" gracias a su investigación, difusión y defensa de las culturales prácticas del Pacífico (Hurtado 75). Los compiladores de la antología también transcribieron sus versos a líderes liberales como los expresidentes Enrique Olaya Herrera (1880 - 1937), Alfonso López Pumarejo (1886 - 1959) y el líder político Jorge Eliécer Gaitán (1898 - 1948).

De igual forma, es necesario destacar que los cuartetos de octosilábicos de Hurtado también se inspiraron en sus experiencias como mujer, negra y pobre en una sociedad racista, capitalista y patriarcal. En el poema "La lucha de enunciación", la autora no solo resume, de manera estratégica, minuciosa y locuaz, el proceso que condujo a la instauración del sufragio femenino en Colombia, en 1961, sino que también enarbola sin miedo su bandera en defensa de los derechos de las mujeres:

\title{
La lucha de Anunciación (el voto de la mujer)
}

\author{
La lucha en que se metían \\ era de siglos atrás, \\ las mujeres se sentían \\ para votar muy capaz. \\ [...] \\ Altercaban los más brutos \\ y otros sabios que ni hablar: \\ "si Anuncia vota hay disgustos \\ y se acaba nuestro hogar".
}

"La mujer es para estar al cuidado de los hijos, pa' barrer, pa' cocinar pero pa' votar ¿quién dijo?”.

(Hurtado 51-52).

El poema anterior se destaca en el mar de escritos que forman parte de nuestro corpus de estudio porque en él, Hurtado cuestiona - desde la perspectiva interseccional del feminismo negro y el feminismo afrolatinoamericano- el clasismo, el racismo y el patriarcado para explicar la vulnerabilidad en la que se encuentran las mujeres colombianas. En los versos, se encuentran discursos que rechazan la opresión a la que son sometidas millones de mujeres no blancas en el Abya Yala y desafían las máscaras silenciadoras de un sistema 
ideológico de dominación patriarcal-racista que las infantiliza, las mantiene ancladas en la base de su jerarquía (sustentada por condiciones biológicas de sexo y raza) y les reprime su humanidad al negarles el derecho a ser sujetos de su propio discurso y de su propia historia (González 141).

\section{Consideraciones finales}

Después de realizar este viaje por las redes poéticas de Margarita Hurtado, se concluye que la narradora ejecutó maniobras de reproducción sociocultural y preservación de los paradigmas ético-estéticos de la diáspora africana, en su constante función de reconstruir y transmitir la memoria colectiva del pueblo afrocolombiano, como forma institucional de cohesión cultural (Maglia y Moñino 177). La antología también se puede catalogar como un corpus diversificado de literatura oral que, dialogando con imágenes culturales y geoespaciales de su memoria colectiva, se consolida como un "lugar de memoria" en el que se entrelazan procesos de recordación comunitarios.

Se considera que las composiciones de la autora se caracterizan por ser engranajes narrativos que protegen y mantienen vivas, como su "canto divino", los holocenos donde descansan las visiones comunitarias del pasado. En cada verso, Margarita viste el traje de las "autoras-pueblo" que transmiten con sus creaciones los valores y estructuras de control social aceptados por los antepasados de la población como parte integral de su espíritu. Su obra también dialoga con los preceptos de los pueblos africanos e indígenas orales que utilizan la tradición oral como mecanismo para promover valores morales, leyes, normas y reglamentos considerados sagrados y necesarios para orientar la vida en los estuarios.

En este sentido, nos encontramos frente a una de los principales portavoces y tejedores de los "Palenques Literarios" que nacieron durante la segunda mitad del siglo xx, como proyecto político de resistencia ancestral y antirracista, cuyo principal estandarte era la defensa de los derechos inalienables de los pueblos afropacíficos. Las formas poéticas tradicionales de estas comunidades fueron utilizadas por Margarita Hurtado como una herramienta pública de movilización política que ayudó a reconstruir memorias colectivas e iluminar los caminos futuros de la comunidad, promoviendo conciencias colectivas y denunciando los ataques seculares del potentado colonial a sus comunidades.

\section{Referencias}

Candau, Joël. Memória e identidade. Traducido por Maria Letícia Ferreira. Sao Paulo, Contexto, 2019. 
Freja de la Hoz, Adrián. La literatura oral en Colombia. Romances, coplas y décimas en el Pacífico y el Caribe colombianos. Bogotá, Editorial Universidad Nacional de Colombia, 2015.

Gómez, Laureano. "Los textos históricos: interrogantes sobre el progreso de Colombia". Boletín Cultural y Bibliográfico, vol. 18, núm. 1 (1981): 5-30. Impreso.

González, Lélia. Por um feminismo afrolatinoamericano. Traducido por Barbara Cruz, Carlos Medeiros, Catalina Zambrano y Tuna Nascimento. Rio de Janeiro, Zahar, 2020.

Halbwachs, Maurice. A memória coletiva. Traducido por Laurent León. Paris, Edições Vértice, 1990.

Hampaté Bâ, Amadou. “A tradição viva”. História geral da África, I: Metodologia e pré-história da Africa. Editado por Joseph Ki-Zerbo. UNESCO, Brasília, 2010.

Hoffmann, Odile. "Espacios y movilidad de la gente negra en el Pacífico Sur colombiano: ¿hacia la construcción de una "sociedad regional"?". Estudos Afro-Asiáticos, vol. 25, núm. 1(2002): 43-74. Web. 20 Jul. 2021. https://doi.org/10.1590/S0101$546 \times 2003000100004$.

Hurtado Castillo, Margarita. Los versos de la Margarita. Alcaldía Municipal de Buenaventura, 1992.

Lawo-Sukam, Alain. “(A)cercamiento al concepto de la negritud en la literatura afro-colombiana”. Cincinnati Romance Review, núm. 30 (2011): 39-52. Web. 26 Sep. 2021. https://scholar.uc.edu/concern/parent/9k41zg13t/file_sets/bk128c34c?locale=en

Maglia, Graciela y Yves Moñino. "Oralitura de San Basilio de Palenque: temas europeos, africanos y criollos”. Revista Cuadernos de Literatura, vol. 19, núm. 38 (2015): 171201. Web. 26 Sep. 2021. https://doi.org/10.11144/Javeriana.cl19-38.osbp

Mignolo, Walter. "Delinking. The rhetoric of modernity, the logic of coloniality and the grammar of de-coloniality". Cultural Studies, vol. 21, núm. 2-3 (2007): 449-514. Web. 16 Sep. 2021. https://doi.org/10.1080/09502380601162647

Ministerio de Cultura. Sabores y saberes del Pacifico colombiano: Buenaventura - Tumaco. Bogotá, Ministerio de Cultura, 2017.

Motta González, Nancy. Hablas de selva y agua: la oralidad afropacifico desde una perspectiva de género. Cali, Editorial de la Universidad del Valle, 1997.

Nora, Pierre. Entre memória e história: a problemática dos lugares. Projeto História, vol. 10 (1993): 7-28. Impreso. 
Ochoa, Juan Sebastián; Convers, Leonor y Oscar Hernández, Óscar. Arrullos y currulaos: material para abordar el estudio de la música tradicional del Pacifico sur colombiano. Bogotá, Editorial Pontificia Universidad Javeriana, 2014. Web. 16 Sep. 2021. http://hdl.handle.net/10554/41255

Ong, Walter. Oralidad y escritura, tecnologías de la palabra. México, Fondo de Cultura Económica, 1996.

Oslender, Ulrich. "Discursos ocultos de resistencia: tradición oral y cultural política en comunidades negras de la costa pacífica colombiana". Revista Colombiana de Antropología, vol. 39 (2003): 203-236. Web. 20 Sep. 2021. https://doi.or$\mathrm{g} / 10.22380 / 2539472 X .1241$

Prado Paredes, Nelly Mercedes. "El origen de los versos para enamorar: oralidad del Pacífico sur de Colombia”. América Negra, núm 12. (diciembre 1996): 190-204. Impreso.

Revelo Hurtado, Baudilio; Revelo González, Camilo y Carolina Revelo González (Comps.). "Presentación". Cuentos para dormir a Isabella. Bogotá, Ministerio de Cultura, 2010, pp. 19-29. Web. 20 Sep. 2021. https://babel.banrepcultural.org/digital/collection/p17054coll7/id/7

Ricoeur, Paul. La memoria, la historia, el olvido. Buenos Aires, Fondo de Cultura Económica de Argentina, 2000.

Valderrama Rentería, Carlos Alberto. "El arte literario y la construcción oral del territorio. Pensamiento crítico afrocolombiano". Revista Colombiana de Antropología, vol. 54, núm. 2 (2018): 93-117. Web. 20 Sep. 2021. https://doi.org/10.22380/2539472X.463

Vanín, Alfredo. “Alianzas y simbolismos en las rutas de los ausentes”. Imágenes de las "culturas negras” del Pacífico colombiano. Documento de Trabajo núm. 40. CIDSE, Centro de Investigaciones y Documentación Socioeconómica de la Universidad del Valle, 1999, pp. 3-18. Impreso.

----. Una mirada a la tradición oral del Pacífico. Bogotá, Banco de la República de Colombia, 2016. Recurso de audio. Web. 20 Sep. 2021. https://babel.banrepcultural.org/ digital/collection/p17054coll18/id/341

Velásquez, Rogerio. "La canoa chocoana en el folklore”. Revista Colombiana de Folclor vol. 3 (1960): 109-126. Impreso. 